Research Paper

\title{
Tissue factor: A potent stimulator of Von Willebrand factor synthesis by human umbilical vein endothelial cells
}

\author{
Muriel Meiring ${ }^{\bowtie}$, W. Allers, E. Le Roux \\ Department of Haematology and Cell Biology, University of the Free State Bloemfontein, South Africa. \\ $\triangle$ Corresponding author: Muriel Meiring; meiringsm@ufs.ac.za
}

(C) Ivyspring International Publisher. Reproduction is permitted for personal, noncommercial use, provided that the article is in whole, unmodified, and properly cited. See http://ivyspring.com/terms for terms and conditions.

Received: 2016.03.29; Accepted: 2016.08.15; Published: 2016.09.20

\begin{abstract}
Inflammation and dysfunction of endothelial cells are thought to be triggers for the secretion of Von Willebrand factor. The aim of this study was to examine the effects of the inflammatory cytokines interleukin-6 (IL-6), interleukin-8 (IL-8) and tumour necrosis factor-alpha (TNF- $\alpha$ ) and the coagulation factors, tissue factor and thrombin on the release and cleavage potential of ultra-large von Willebrand factor (ULVWF) and its cleavage protease by cultured human umbilical vein endothelial cells (HUVEC). HUVEC were treated with IL-6, IL-8, and TNF- $\alpha$, tissue factor (TF) and thrombin, and combinations thereof for 24 hours under static conditions. The cells were then exposed to shear stress after which the VWF-propeptide levels and the VWF cleavage protease, ADAMTS13 content were measured. All treatments and their combinations, excluding IL-6, significantly stimulated the secretion of VWF from HUVEC. The VWF secretion from the HUVEC was stimulated most by the combination of TF with TNF- $\alpha$. Slightly lower levels of ADAMTS13 secretion were found with all treatments. This may explain the thrombogenicity of patients with inflammation where extremely high VWF levels and slightly lower ADAMTS1 3 levels are present.
\end{abstract}

Key words: Endothelium, Von Willebrand factor, ADAMTS13, Inflammation.

\section{Introduction}

To date, extensive progress has been made in the knowledge of inflammation. It is now known that, pro-inflammatory mediators are released or produced from the surrounding tissue and cellular components such as mast cells after injury [1]. Under inflammatory conditions, the endothelium responds by regulating its own permeability and releases pro-inflammatory mediators such as cytokines. Among the pro-inflammatory cytokines, tumour necrosis factor- $\alpha$ (TNF-a), interleukin-6 (IL-6) and interleukin-8 (IL-8) have been implicated as the primary endogenous mediators of inflammation [2]. IL-6 up-regulates fibrinogen, tissue factor, Von Willebrand factor (VWF), and factor VIII levels [3,4]. IL-6, IL-8, and TNF-a were shown to have stimulatory effects on the endothelial cell release of ULVWF multimers, but not on the cleavage of ULVWF by ADAMTS13 [5]. Thrombin has also stimulatory effects on the endothelial cell release of ULVWF multimers [6]. Its effect on ADAMTS13 synthesis has not been studied. The stimulatory effect of TF on endothelial cells to release ULVWF and ADAMTS13 has also not been studied.

The increased amounts of VWF multimers due to entothelium stimulation with these cytokines, then might bind platelets to form thrombi in small vessels. A disintegrin-like metalloprotease with thrombospondin type I repeats-no 13 (ADAMTS13) released from endothelial cells cleaves the VWF multimers into smaller and less active forms. These VWF multimers mediate the initial adhesion of activated platelets, the first step in thrombus formation. This process may be affected by the amount of VWF and ADAMTS13 secreted [7].

Ultimately, the increased VWF levels and the decreased ADAMTS13 levels contribute to the development of thrombotic and inflammatory diseases, such as sepsis, antiphospholipid syndrome, 
atherosclerosis, systemic schlerosis, diabetes and thrombotic thrombocytopenic purpura (TTP) [8-11]. The extremely high VWF levels and slightly lower ADAMTS13 levels in these patients are not completely understood.

This study examines the effects of the most commonly present inflammatory cytokines (IL6, IL8 and TNF- $\alpha$ ) and coagulation factors (tissue factor and thrombin) and especially combinations thereof on the secretion of VWF and ADAMTS13 by cultured HUVEC. For optimal VWF-propeptide and ADAMTS13 secretion, we used sub-confluent and fourth passage cells [12-14]. This might enable us to determine the highest contributing factors to the extremely high VWF levels and slightly lower ADAMTS13 levels in patients with thrombotic disorders.

\section{Materials and Methods}

\section{Procedure}

Cultured human umbilical vein endothelial cells (HUVEC) were stimulated with cytokines IL-6 (100 $\mathrm{ng} / \mathrm{mL}), \mathrm{IL}-8,(100 \mathrm{ng} / \mathrm{mL})$ and TNF-a $(100 \mathrm{ng} / \mathrm{mL})$ and also with coagulation factors, thrombin (2 $\mathrm{IUn} / \mathrm{mL})$ and TF $(662 \mathrm{ng} / \mathrm{mL})$ and combinations of these compounds. The combinations include that of IL-8 and thrombin, IL-8 and TF, TNF-a and thrombin and TNF- $a$ and TF. The control for the model was untreated cells for each treated sample.

\section{Endothelial cell culture}

HUVEC cell line C-003-5C (Invitrogen, USA) were maintained in round $22.1 \mathrm{~cm}^{2}$ fibronectin (10ng/mL, Invitrogen, USA) coated tissue culture dishes at a concentration of $1.25 \times 10^{4}$ cells $/ \mathrm{mL}$ with a volume of $5 \mathrm{ml}$ per culture dish. The cells were cultured in Medium 200 supplemented with Low Serum Growth Supplement (LSGS, Invitrogen) containing foetal bovine serum (FBS), hydrocortisone, human epidermal growth factor, basic fibroblast growth factor and heparin in a humidified $37^{\circ} \mathrm{C}, 5 \%$ $\mathrm{CO}_{2} / 95 \%$ air cell culture incubator. We cultured the HUVEC in the flasks for approximately 3 days until the confluency was estimated to be $80 \%$. Sub-culturing was done with Trypsin/EDTA $(0.025 \%$ Trypsin / 0.01\% EDTA solution) at room temperature for 3 minutes whereafter the action of Trypsin/EDTA was blocked by $3 \mathrm{~mL}$ of Trypsin Neutralizer solution (Invitrogen, USA). Only 4th-passaged HUVEC were used for all experiments. HUVEC were used, since it is a major endothelial cell type that produces ADAMTS13 in humans and it is readily available and the results are comparable [5, 12-16]. Human umbilical vein endothelial cells are also capable of expressing VWF and also carry ADAMTS13, which makes it a viable option for VWF research $[17,18]$.

\section{Cell culture treatments under shear stress}

The $4^{\text {th }}$-passaged HUVEC were grown until confluent on all tissue culture dishes. Thereafter, the old medium was discarded and the dishes prepared for treatment. The HUVEC were stimulated with inflammatory cytokines, IL-6, IL-8 and TNF- $\alpha$ (Invitrogen, USA) and also with human TF (Innovin, Siemens, South Africa) and bovine thrombin (Beckman Coulter, South Africa). This was done by incubating the cells for $24 \mathrm{hrs}$ with the different compounds and combinations of the cytokines respectively before applying shear stress. Six culture flasks were used for each stimulant, three for the control (untreated) and three for the treatment (treated). The final concentration for each treatment was prepared in $5 \mathrm{~mL}$ of supplemented Medium 200. The following final concentrations were used for the inflammatory cytokines: $0 \mathrm{ng} / \mathrm{mL}$ as control, and 100 $\mathrm{ng} / \mathrm{mL}$ as treatment. For thrombin, $0 \mathrm{IUnits} / \mathrm{mL}$ as control, and 2 IUnits/ $\mathrm{mL}$ as treatment and for tissue factor $0 \mathrm{ng} / \mathrm{mL}$ as control, and $662 \mu \mathrm{l} / \mathrm{mL}$ as treatment were used. The same concentrations of the stimulants were used for the combinations as for the different compounds alone. The cytokine concentrations were based on the experiments done by Bernardo et al. (2004) and Cao et al. (2008) who used the same concentrations [5, 7]. The coagulation factor concentrations were determined by a previous non-published dose-response study.

After the treatment period, the control and stimulated dishes were carefully removed from the incubator, and placed onto a ROTEM orbital shaker for 1 hour to generate a wall shear stress of about 2.5 dynes $/ \mathrm{cm}^{2}$. It is known that under shear stress conditions, VWF becomes more susceptible to proteolysis by ADAMTS13. This shear stress is necessary for HUVEC to exposed VWF to proteolysis [19-20]. The concentration of the treatment cytokines and coagulation factors were assumed to stay constant during the treatment and rotation process, since evaporation was negligible. Lastly, the flasks were removed from the ROTEM and the perfusate collected, aliquoted and stored at $-80^{\circ} \mathrm{C}$ until the measurements were performed.

\section{ADAMTS13 levels}

Due to the expected low ADAMTS13 levels, the ADAMTS13 release was detected using a sodium dodecyl-sulphide - poly-acrylamide gel-electrophorsis (SDS-PAGE), followed by Western-blot detection. The SDS-PAGE was prepared and performed using a $12 \%$ separating gel and a $4 \%$ stacking gel. Following SDS-PAGE, the gel was 
blotted onto a PVDF membrane (Thermo Scientific, USA). The PVDF membrane first blocked with $2 \%$ skimmed milk powder in TBS- $0.1 \%$ Tween-20 for 1 hour at room temperature and washed 6 times with TBS- $0.1 \%$ Tween-20. The membrane was then incubated for 2 hours at room temperature in a 1:100 dilution of a rabbit polyclonal IgG antibody against human ADAMTS13 (Santa Cruz Biotechnology, CA, USA). After washing again, it was incubated for 1 hour at room temperature with a polyclonal goat antirabbit antibody conjugated with horseradish peroxidise (HRP) (1:2,000 dilution, Santa Cruz Biotechnology, CA, USA) to detect the presence of ADAMTS-13. Equal volumes of ECL Western-blot detection reagent 1 and 2 (AEC Amersham, UK) were mixed and poured onto the membrane for 1 minute whereafter the membrane was sealed with plastic film and exposed to an X-ray film for 1 to 10 minutes in the dark. Finally, the film was developed in an automated film developer (Kodak, CA, USA) and the picture was scanned into a computer. The strength of the signal of ADAMTS13 was quantified by densitometric analysis using the ImageJ software (Thermo Scientific, USA). itometric analysis of ADAMTS13 content was done and the percentage difference from the control was calculated by dividing the difference in density for each treated sample from the density for the control by the density of the control sample.

\section{VWF-propeptide levels}

VWF-propeptide levels in the perfusates were determined using an in-house ELISA. In short, a 96-well ELISA plate was coated overnight at $4^{\circ} \mathrm{C}$ with a monoclonal antibody against the VWF-propeptide (CLB-Pro 35, Euro-Immune, Germany, 1:100 dilution in PBS, $100 \mu \mathrm{l}$ per well). The plate was blocked with $4 \%$ bovine serum albumin (BSA) in PBS (200 $\mu \mathrm{l} /$ well) for 2 hours at room temperature and washed four times with PBS/0.1\%Tween-20. The perfusates were added in duplicate (100 $\mu \mathrm{l} /$ well) and incubated for 2 hours at $37^{\circ} \mathrm{C}$. An HRP-conjugated monoclonal antibody against VWF-propeptide (CLB-Pro 14.3, Euro-immune, Germany) was added in a 1:100 dilution after another wash step, and incubated for 1 hour at room temperature in order to detect the concentration of VWF-propeptide in the perfusate. We used OPD (50 mg.L-1) as the substrate for HRP. The WHO's (World Health Organisation) $6^{\text {th }}$ FVIII/VWF standard was used as the standard against which the perfusates were measured. The results were expressed as percentage difference from the control samples. Thus (VWF-propeptide level of stimulated sample minus VWF-propeptide level of control) / VWF-propeptide level of control * 100.

\section{Statistics}

It is important to notice that the whole experiment was done three times. Thus for each stimulant we culture 6 flasks, three control and three treated flasks, and each perfusate was measured in duplicate for the ADAMTS13 and VWF-propeptide levels. The percentage increase or decrease from the control samples was calculated and all the experimental data were presented as mean \pm SD (standard deviation). The unpaired 2-tailed Student t-test was used to test for differences and P- values less than $0.05(\mathrm{P}<0.05)$ were considered as statistically significant.

\section{Results}

Figure 1 shows the densitometic analysis of the ADAMTS13 content in the stimulated samples. This is expressed as percentage difference from the control samples. The original Western-blot picture is shown in Figure 2. An overall decrease in density of the stimulated samples compared to that of the controls is clearly visible.

\section{Perfusate ADAMTS13 relative density}

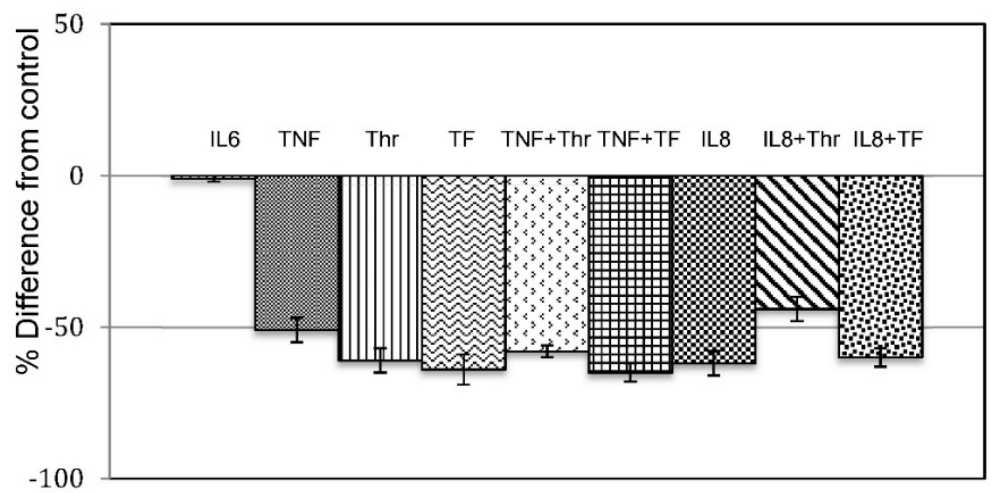

Figure 1. Effect of cytokines (IL6. and TNF), coagulation factors (Thr and TF) and combinations thereoff (TNF+Thr, TNF+TF) on ADAMTS13 levels in the perfusates. The bar graphs shows the mean \% difference from the control of the 3 experiments done in duplicate $(n=3)$ and the error bars indicates the standard deviation. 

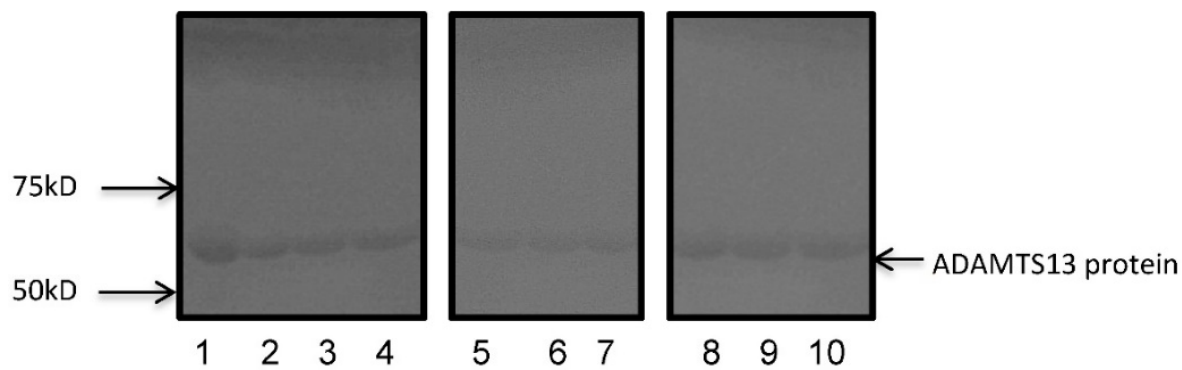

Figure 2. Western Blot indicating the presence of the ADAMTS13 protein in all samples. The positions of the molecular markers are shown on the left side. For illustration purposes, only some of the samples are shown. Not stimulated sample (lane 1), IL6 (lane 2), IL8 (lane 3), TNF $\alpha$ (lane 4), thrombin (lane 5), tissue factor (lane 6), IL8 + thrombin (lane 7), TNF $\alpha+$ thrombin (lane 8), IL8 + tissue factor (9) and TNF $\alpha+$ tissue factor (lane 10).

\section{Perfusate VWF-propeptide level}

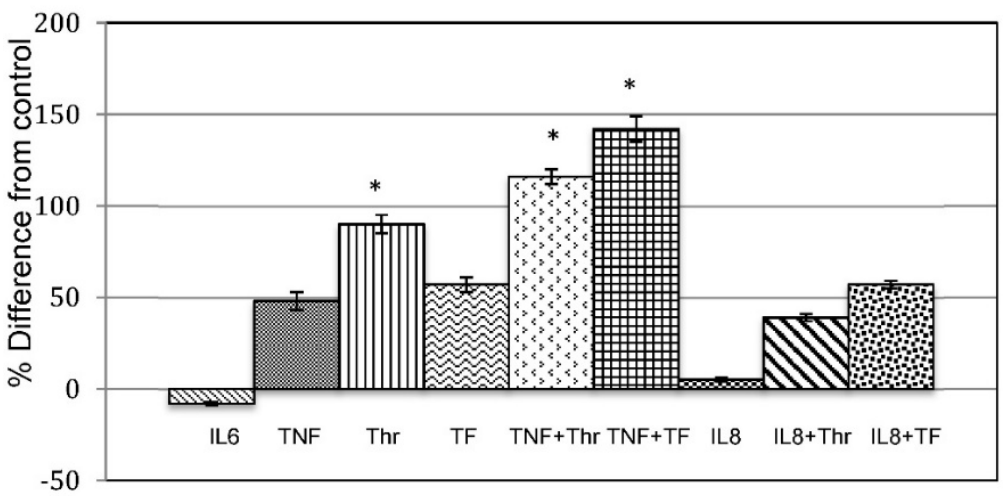

Figure 3. Effect of cytokines (IL6, IL 8 and TNF), coagulation factors (Thr and TF) and combinations thereof (TNF+Thr, TNF+TF, IL $8+T h r$ and IL8+TF) on VWF-propeptide levels. The bar graphs shows the mean \% difference from the control of the 3 experiments done in duplicate and the error bars indicates the standard deviation. The $*$ indicates statistic significance $(p<0.05)$.

The percentage difference of all stimulated samples, except for IL-6 to that of the control samples ranged between a ratio of 30 to $60 \%$. Although this was not a quantitative measurement, it nevertheless showed that the ADAMTS13 secretion was decreased when endothelial cells were stimulated with IL-8, TNF- $a$, thrombin and TF and combinations of TF and thrombin with the cytokines (IL-6 had no effect).

In summary, endothelial cells (HUVEC) stimulated with cytokines and coagulation factors secreted more VWF and less ADAMTS13.

The VWF-propeptide levels rather than VWF antigen levels were measured in the perfusate, since it provides a more accurate measurement of VWF synthesis [21]. Figure 3 shows the mean percentage change from the controls, while table 1 provides the original data of the VWF-propeptide levels in the control and treated samples.

VWF-propeptide were secreted by all treatments, except for IL-6. The amount of VWF-propeptide was secreted from the lowest to the highest values by the following treatments: IL-8, IL-8+thrombin, TNF- $\mathrm{a}$, thrombin, TNF- $\mathrm{a}$, TNF-a+thrombin, tissue factor, IL-8+tissue factor, and with the highest increase seen at TNF- $\alpha+$ tissue factor treatment. Treatments with thrombin, TNF- $\alpha$ and thrombin and TNF- $\alpha$ and tissue factor shows a significant increase in VWF propeptide levels compared to that of the control.

Table 1. Effect of cytokines (IL6, IL8 and TNF), coagulation factors (Thr and TF) and combinations thereoff (TNF+Thr, TNF+TF, IL8+The and IL8+TF) on VWF-propeptide levels (\%).

\begin{tabular}{llll}
\hline Stimulant & $\begin{array}{l}\text { \% VWF-propeptide } \\
\text { of Control } \\
\text { (mean } \pm \text { SD) }(\mathrm{n}=6)\end{array}$ & $\begin{array}{l}\text { \% VWF-propeptide } \\
\text { of Treated } \\
(\text { mean } \pm \text { SD) }(\mathrm{n}=6)\end{array}$ & $\begin{array}{l}\text { Percentage } \\
\text { increase } \\
\text { from control } \\
(\text { mean } \pm \text { SD) }\end{array}$ \\
\hline IL-6 & $56.5 \pm 1$ & $52 \pm 1$ & $(-) 8 \pm 1$ \\
TNF & $54 \pm 1.5$ & $104.5 \pm 2.5$ & $48 \pm 5$ \\
Thr & $73.5 \pm 4$ & $140 \pm 5$ & $90 \pm 5 *$ \\
TF & $47.5 \pm 2$ & $109.5 \pm 4.5$ & $57 \pm 4$ \\
TNF + Thr & $64.5 \pm 2$ & $139 \pm 5$ & $116 \pm 6^{*}$ \\
TNF + TF & $54 \pm 2$ & $130.5 \pm 5$ & $142 \pm 4 *$ \\
IL-8 & $21 \pm 1$ & $23.5 \pm 1.5$ & $5 \pm 1$ \\
IL-8+ Thr & $27 \pm 1$ & $44.5 \pm 2$ & $39 \pm 2$ \\
IL-8 + TF & $20 \pm 3$ & $30.5 \pm 2$ & $53 \pm 6$ \\
\hline
\end{tabular}

The results are given as the mean of 3 experiments in duplicate \pm 1 standard deviation $(n=6)$. The * indicates statistic significance at $p<0.05$.

The levels of secreted VWF-propeptide, except for IL-6 which cause a decrease, increased in the following order from low to high: IL-8, IL-8+thrombin, TNF- $\alpha$, thrombin, TNF- $\alpha$, TNF- $\alpha+$ thrombin, tissue factor, IL- $8+$ tissue factor, and 
with the highest increase the TNF- $\alpha$ +tissue factor treatment. Only stimulation with Thrombin, TNF- $\alpha+$ thrombin and TNF- $\alpha+$ tissue factor increased the VWF-propeptide levels significantly.

\section{Discussion}

We hypothesized that the combination of certain inflammatory cytokines and coagulation factors that are released during inflammation may stimulate the synthesis and release of VWF and simultaneously slightly decrease the synthesis of ADAMTS13. This might result in a thrombotic state where excessive amounts of VWF-platelet strings cannot be degradated and might occlude small vessels.

To test this hypothesis, we determined the effects of 3 inflammatory cytokines, interleukin-6 (IL-6), interleukin-8 (IL-8) and tumour necrosis factor- $\alpha$ (TNF-a), which are released during the early stages of systemic inflammation on the secretion of VWF and its cleaving protease ADAMTS13 in human primary HUVEC. This study presents the first in vitro evidence on the effects of thrombin and tissue factor, combined with inflammatory cytokines, on VWF synthesis and cleavage in HUVEC.

Since VWF becomes more susceptible to proteolysis by ADAMTS13 during shear stress, we used a fluid shear stress of $2.5 \mathrm{dyne} / \mathrm{cm}^{2}$ for a small time period to ensure the expression of the VWF-propeptide and ADAMTS13 [20, 21]. The VWF-propeptide levels were measured instead of the VWF antigen levels, since it is a more accurate measurement of VWF secretion [21].

IL-6 was the only cytokine that did not affect VWF-propeptide and ADAMTS13 secretion (Table 1, Figure 1). However, this was expected because HUVEC do not have receptors for IL-6 [22, 23]. This result confirmed the findings of Bernardo et al. (2004), who reported that IL-6 alone does not stimulate the VWF synthesis from HUVEC [5]. However, IL-6 in complex with its receptor on other endothelial cells induced a small but significant release of VWF [5].

The VWF-propeptide levels increased when HUVEC was stimulated with TNF-a (Table 1). This supports the results of other similar studies [5, 16, 24]. The precise mechanism through which TNF-a induces this increase is unknown [25]. In accordance with Cao et al. (2008), which found lower ADAMTS-13 mRNA levels after 24-hour treatment with $10 \mathrm{ng} / \mathrm{mL}$ TNF- $\alpha$, we also found that TNF- $\alpha$ induced a decreased ADAMTS13 release [7].

IL-8 did not stimulate the secretion of VWF by HUVEC. It however induced a decrease in HUVEC ADAMTS13 levels (Fig. 1). To date, no studies have been done on the effect of IL-8 treatment on ADAMTS13 release.
We found no evident change in the HUVEC ADAMTS13 release upon stimulation with TF. This correlates with studies where shiga toxin was used to stimulate TF expression. Cells treated with shiga toxin also did not increase or decrease the ADAMTS13 levels [26, 27].

This is also the first time where the effect of tissue factor was tested on VWF secretion in HUVEC cells. Tissue factor increased VWF secretion markedly. The highest increase was when HUVEC was stimulated by the combination of tissue factor and TNF- a (Table 1). It is however not clear if TF can be linked to increased VWF-propeptide levels in vivo [28-30]. However, in HIV where TF levels are increased, it is possible that the constant stimulation of VWF release by tissue factor might contribute to the extremely high levels of VWF in these patients [31].

Our results with IL-8 and TNF-a-stimulation were consistent with a study done by Bernardo et al., (2004) who indicated a similar effect of IL-8 and TNF-a on VWF synthesis by endothelial cells [5].

We found total opposite results with ADAMTS13 compared to VWF-propeptide in the perfusates. IL-8, TNF- $\alpha$, tissue factor, IL-8+tissue factor and TNF- $\mathrm{a}+$ tissue factor decreased the levels of ADAMTS13 (Fig. 1). Although the results with the different stimulation regimes were not significantly different, the decrease with all stimulation regimes were substantial. The affected decrease in release of ADAMTS13 in human umbilical endothelial cells by IL-8, TNF-a, thrombin and tissue factor and their combined effects, may offer a logical explanation of how systemic inflammation and/or infection might trigger a thrombotic condition.

We suggest that certain inflammatory cytokines and coagulation factors that are released during pathological conditions may affect the balance between the quantity of VWF multimers and ADAMTS13 released from endothelial cells. More VWF and VWF-propeptide might be secreted and less ADAMTS13. As a result, the excessive amounts of VWF, with lesser amounts of the VWF cleavage protease, ADAMTS13, might cause obstructions of platelet-VWF plugs in smaller vessels, leading to thrombosis [27, 29-31]. This should be investigated further in more detail.

\section{Conclusion}

We investigated the effect of inflammatory and thrombotic stimuli and the combination thereof on the release of VWF and its cleavage protease ADAMTS13 by human umbilical vein endothelial cells (HUVEC). Tissue factor and especially the combination of TF and TNF- $\alpha$ was the most potent stimulator of von Willebrand factor secretion by HUVEC. Thus, the 
results in this study may provide a link between inflammation and thrombosis, which may also be of therapeutic importance. It may also help to understand the mechanisms that lead to thrombotic disorders with increased VWF levels and lower ADAMTS13 levels.

\section{Acknowledgement}

This study was done with a grant from the National Research Foundation of South Africa.

\section{Competing Interests}

The authors have declared that no competing interest exists.

\section{References}

1. Granger $\mathrm{DN}$ and Kubes P. The microcirculation and inflammation: modulation of leukocyte-endothelial cell adhesion. J Leukoc Biol. 1994; 55: 662-675

2. Tracey KJ and Cerami A. Tumor necrosis factor: a pleiotropic cytokine and therapeutic target. Annu Rev Med. 1994; 45: 491-503.

3. Neumann FJ, Ott I, Marx N, et al. Effect of human recombinant interleukin-6 and interleukin-8 on monocyte procoagulant activity. Arterioscler Thromb Vasc Biol. 1997; 17: 3399-3405.

4. Kerr R, Stirling D, Ludlam C. Interleukin-6 and haemostasis. Br J Haematol. 2001; 115: 3-12.

5. Bernardo A, Ball C, Nolasco L, et al. Effects of Inflammatory Cytokines on the Release and Cleavage of the Endothelial Cell-Derived Ultra-large Von Willebrand Factor Multimers Under Flow. Blood. 2004; 104: 100-106.

6. Wagner DD. New links between inflammation and thrombosis. Arterioscler Thromb Vasc Biol. 2005; 25: 1321-1324.

7. Wang A, Duan O, Liu X, et al. All-trans retinoic acid modulates the balance of ADAMTS13 and VWF in human micro-vascular endothelial cells. Microvasc Res. 2015; 102: 6-10.

8. Habe K, Wada H, Ito-Habe N, et al. Plasma ADAMTS13, Von Willebrand Factor (VWF) and VWF Propeptide Profiles in patients with DIC and related diseases. Thromb Res. 2012; 129: 598-602.

9. Scheja A, Akesson A, Geborek P, et al. Von Willebrand Factor propeptide as a marker of disease activity in systemic sclerosis (scleroderma). Arthritis Res. $2001 ; 3: 178-182$

10. Vischer UM, Emeis JJ, Bilo HJG, et al. Von Willebrand Factor as a plasma Marker of endothelial activation in diabetes: Improved reliability with parallel determination of the VWF propeptide (VWF:AgII). Thromb Haemost. 1998; 80: $1002-7$

11. Van Mourik J, Romani de Wit T, et al. Von Willebrand Factor Propeptide in vascular disorders. Thromb Haemost. 2001; 86: 164-71.

12. Hussein MNA, Böing AN, Biró É, et al. Phospholipid Composition of In Vitro Endothelial Microparticles and Their In Vivo Thrombogenic Properties. Thromb Res. 2008; 121: 865-871.

13. Luu NT, Rahman M, Stone PC, et al. Responses of Endothelial Cells From Different Vessels to Inflammatory Cytokines and Shear Stress: Evidence for the Pliability of Endothelial Phenotype. J Vasc Res. 2010; 47: 451-461.

14. Laflamme K, Roberge CJ, Pouliot S, et al. Tissue-engineerd human vascular media produced in vitor by the self-assembly approach present ifunctional properties similar to those of their native blood vessels. Tissue Eng. 2006; 12: 2275-2281

15. Inoguchi $\mathrm{H}$, Tanaka $\mathrm{T}$, Maehara $\mathrm{Y}$ et al. The effect of gradually graded shear stress on the morphological integrity of huvec-seeded compliant small-diameter vascular graft. Biomaterials. 2007; 28: 486-495.

16. Combes V, Simon A, Grau G, et al. In Vitro Generation of Endothelial Microaprticles and Possible Prothrombotic Activity in Patients with Lupus Anticoagulant. J Clin Invest. 1999; 104: 93-102.

17. Turner N, Nolasco L, Tao Z, et al. Human Endothelial Cells Synthesise and Release ADAMTS-13. J Thromb Haemost. 2006; 4: 1396-1404.

18. Liu J, Yuan L, Molema G, et al. Vascular Bed-Specific Regulation of the Von Willebrand Factor Promotor in the Heart and Sceletal muscle. Blood. 2011; 117: 342-351.

19. Sargent CY, Berguig GY, Kinney MA, Hiatt LA, et al. Hydrodynamic modulation of embryonic stem cell differentiation by rotary orbital suspension culture. Biotechnol Bioeng. 2010; 105: 611-626.

20. Dong J, Moake JL, Nolasco L, et al. ADAMTS-13 Rapidly Cleaves Newly Secreted Ultralarge Von Willebrand Factor Multimers on the Endothelial Surface Under Flowing Conditions. Blood. 2002; 100: 4033-4039.

21. Ragni MV. On the cutting edge: von Willebrand factor propeptide and thrombosis. J Thromb Haemost. 2006; 4: 2553-2555.
22. Romano $\mathrm{M}$, Sironi $\mathrm{M}$, Toniatti $\mathrm{C}$, et al. Role of IL-6 and its soluble receptor in induction of chemokines and leukocyte recruitment. Immun. 1997; 6: 315-325.

23. Peters M, Müller AM, Rose-John S. Interleukin-6 and soluble interleukin-6 receptor: direct stimulation of gp130 and hematopoiesis. Blood 1998; 92: 3495-3504.

24. Jy W, Jimenez JJ, Mauro LM, et al. Endothelial Microparticles Induce Formation of Platelet Aggregates Via a Von Willebrand Factor/Ristocetin Dependent Pathway, Rendering them Resistant to Dissociation. J Thromb Haemost. 2005; 3: 1301-1308.

25. Curtis AM, Wilkinson PF, Gui M, et al. P38 Mitogen-Activated Protein Kinase Targets the Production of Proinflammatory Endothelial Microparticles. J Thromb Haemost. 2009; 7: 701-709.

26. Nestoridi E, Kushak RI, Duguerre D, et al. Up-Regulation of Tissue Factor Activity on Human Proximal Tubular Epithelial Cells in Response to Shiga Toxin. Kidney Int. 2005; 67: 2254-2266.

27. Nolasco LH, Turner NA, Bernardo A, et al. Hemolytic Uremic Syndrome-Associated Shiga Toxins Promote Endothelial-Cell Secretion and Impair ADAMTS13 Cleavage of Unusually Large Von Willebrand Factor Multimers. Blood. 2005; 106: 4199-4209.

28. Lip GYH. The Prothrombotic State in Atrial Fibrillation: The Atrium, The Endothelium and Tissue Factor? Thromb Res. 2003; 111: 133-135.

29. Sato M, Suzuki A, Nagata K, et al. Increased Von Willebrand Factor in Acute Stroke Patients with Atrial Fibrillation. J Stroke Cerebrovasc Dis. 2006; 15: 1-7.

30. Yamashita A, Sumi T, Goto S, et al. Detection of Von Willebrand Factor and Tissue Factor in Platelets-Fibrin Rich Coronary Thrombi in Acute Myocardial Infarction. Am J Cardiol. 2006; 97: 26-28.

31. Meiring M, Webb M, Goedhals D, et al. HIV-associated thrombotic thrombocytopenic Purpura - What we know so far. Eur Oncol Haematol. 2012; 8(2): 89-91. 